\title{
U.S. Telecommunications Today
}

\section{By Nicholas Economides*}

Forthcoming, Business Economics, April 1998, Volume XXXIII, Number 2.

*Nicholas Economides is Professor of Economics at the Stern School of Business, New York University, NY. WWW: http://raven.stern.nyu.edu/networks/

This paper reviews the current conditions in the U.S. telecommunications industry. It first examines the impact of technological and regulatory change on market structure and business strategy, and then the impact on pricing of digitization and the emergence of internet telephony. Then the paper considers the effects of the 1996 Telecommunications Act on market structure and strategy in conjunction with the history of regulation and antitrust intervention in the telecommunications sector. After discussing the impact of wireless technologies, the paper concludes with some short-term predictions, as well as concern about the derailment of the implementation of the 1996 Act by aggressive legal tactics of entrenched monopolists (the local exchange carriers), and the real danger that the intent of Congress in passing the 1996 Act to promote competition in telecommunications will not be realized.

Presently, the U.S. telecommunications industry is going through a revolutionary change. There are three reasons for this.

The first reason is the rapid technological change in key inputs of telecommunications services and in complementary goods, which have reduced dramatically the costs of traditional services and have made many new services available at reasonable prices. Cost reductions have made feasible the world wide web ("WWW") and the various multimedia applications that "live" on it.

The second reason for the revolutionary change has been the sweeping digitization of the telecommunications and the related sectors. The underlying telecommunications technology has become digital. Moreover, the consumer and business telecommunications interfaces have become more versatile and closer to multifunction computers than to traditional telephones. Digitization and integration of telecommunications services with computers create significant business opportunities and impose significant pressure on traditional pricing structures, especially in voice telephony.

The third reason for the current upheaval in the telecommunications sector was the passage of a major new law to govern telecommunications in the United States, the Telecommunications Act of 1996 (1996 Act). Telecommunications has been traditionally subject to a complicated federal and state regulatory structure. The 1996 Act attempted to adapt the regulatory structure to technological reality, but various legal challenges by the incumbents have so far delayed, if not nullified, its impact.

Before going into a detailed analysis, it is important to point out the major driving forces in U.S. telecommunications today:

1. Dramatic reductions in the costs of transmission and switching;

2. Digitization; 
3. Restructuring of the regulatory environment through the implementation of the 1996 Telecommunications Act coming twelve years after the breakup of AT\&T;

4. Move of value from underlying services (such as transmission and switching) to the interface and content;

5. Move toward multifunction programmable devices with programmable interfaces, such as computers, and away from single-function, nonprogrammable consumer devices, such as traditional telephone appliances;

6. Reallocation of electromagnetic spectrum, allowing for new types of wireless competition;

7. Interconnection and interoperability of interconnected networks; standardization of communications protocols;

8. Network externalities and critical mass.

These forces have a number of consequences:

1. Increasing pressure for cost-based pricing of telecommunications services;

2. Price arbitrage between services of the same time immediacy requirement;

3. Increasing competition in long distance services;

4. The possibility of competition in local services;

5. The emergence of internet telephony as a major new telecommunications technology.

\section{TECHNOLOGICAL CHANGE}

The past two decades have witnessed dramatic reductions in costs of transmission through the use of technology, reductions in costs of switching and information processing because of big reductions of costs of integrated circuits and computers; and very significant improvements in software interfaces. Cost reductions and better interfaces have made feasible many data- and transmission-intensive services. These include many applications on the world wide web, which were dreamed of many years ago but only now became economically feasible.

The general trend in cost reductions has allowed for entry of more competitors in many components of the telecommunications network and an intensification of competition. Mandatory interconnection of public telecommunications networks and the use of common standards for interconnection and interoperability created a "network of networks," i.e., a web of interconnected networks. The open architecture of the network of networks allowed for entry of new competitors in markets for particular components, as well as in markets for integrated endto-end services. Competition intensified in many, but not all, markets.

\section{Digital Convergence and "Bit Arbitrage"}

Entry and competition were particularly helped by the open architecture of the network and its increasing digitization. Currently, all voice messages are digitized close to their origination and are carried in digital form over most of the network. Thus, the data and voice networks are one, with voice treated as data with specific time requirements. This has important implications on pricing and market structure.

Digital bits (zeros or ones) traveling on the information highway can be parts of voice, still pictures, video, or of a database or other computer application, and they appear identical, "a bit is a bit is a bit." However, because some demands are for real-time services while others are not, the saying that "a bit is a bit is a bit" is correct only among services that have the same index of time immediacy. Digitization implies arbitrage on the price of bit transmission among services that have the same time immediacy requirements.

For example, voice telephony and video conferencing require real-time transmission and interaction. Digitization implies that the cost of transmission of voice is hundreds of times 
smaller than the cost of transmitting video of the same duration. This implies that, if regulatorily-imposed price discrimination is eliminated, arbitrage on the price of bits will occur, leading to extremely low prices for services, such as voice, that use relatively very few bits. Even if price discrimination remains imposed by regulation, arbitrage in the cost and pricing of bits will lead to pressures for a de facto elimination of discrimination. This creates significant profit opportunities for the firms that are able to identify the arbitrage opportunities and exploit them.

\section{Internet Telephony}

The elimination of price discrimination between voice and data services can lead to dramatic reductions in the price of voice calls, precipitating significant changes in market structure. These changes were first evident in the emergence of the Internet, a ubiquitous network of applications based on the TCPIP protocol. Started as a text-based network for scientific communication, the Internet grew dramatically in the late 1980s and 1990s, once not-text-only applications became available. ${ }^{1}$ The Internet now reaches about half a billion computers, most of which are connected through the telephone network. Internet-based telecommunications are based on TCPIP packet switching. There are two modes of operation: a time-delay mode in which there is a guarantee that system will do whatever it can to deliver all packets; and a real-time mode, in which packets can in fact be lost without possibility of recovery.

Most telecommunications services do not have a real-time requirement, so applications that "live" on the Internet can easily accommodate them. For example, there are currently a number of companies that provide facsimile services on the Internet, where all or part of the transport of the fax takes place over the Internet. Although the Internet was not intended to be used in realtime telecommunications, in spite of the loss of packets, presently telecommunications companies use the Internet to complete ordinary voice telephone calls. Voice telecommunications service started on the Internet as a computer to computer call. About three years ago, Internet telecommunications companies started offering termination of calls on the public switched network. In 1996, firms started offering Internet calling that originated and terminated on the public switched network ("PSTN"), i.e., from and to the regular customers' phone appliances. The last two transitions became possible with the introduction of PSTNInternet interfaces and switches by Lucent and others.

Internet calls are TCPIP-packet based. Because they utilize the real time mode of the Internet, there is no guarantee that all the packets of a voice transmission will arrive to the destination. Internet telephony providers use sophisticated voice sampling methods to decompose and reconstitute voice, so that packet losses do not make a significant audible difference. Because such methods are by their nature imperfect, the quality and fidelity of an Internet call depends crucially on the percentage of packets that are lost in transmission and transport. This, in turn, depends, among other factors, on the allocation of internet bandwidth (pipeline) to the phone call, and on the number of times the message is transmitted. ${ }^{2}$

Internet-based telecommunications services pose a serious threat to traditional telecommunications services providers, especially long-distance service providers. In the present U.S. regulatory structure, a call originating from a computer to an Internet service provider ("ISP") (or terminates to a computer) is not charged an "access charges" by the local exchange carrier. This can lead to substantial savings.

In response to the Internet telephony threat, on January 26, 1998, AT\&T announced that it will offer a new long distance service carried over the Internet and intranet. AT\&T's service offered at 7.5-to 9 cents per minute, will originate and terminate on the public switched network ("PSTN") and therefore will appear to customers like a regular call; no computer will be

required. In November 1997, Deutsche Telecom (DT) introduced Internet long-distance service 
within Germany. To compensate for the lower quality of voice transmission, DT offers Internet long distance at one-fifth of its regular long-distance rates. Internet telephony is the most important challenge to the telecommunications sector.

\section{THE 1996 TELECOMMUNICATIONS ACT AND ITS IMPACT}

\section{Goals of the Act}

The Telecommunications Act of 1996 attempts a major restructuring of the U.S. telecommunications sector. The 1996 Act will be judged favorably to the extent that it allows and facilitates the acquisition by consumers of the benefits of technological advances. Such a function requires the promotion of competition in all markets. This does not mean immediate and complete deregulation. Consumers must be protected from monopolistic abuses in some markets as long as such abuses are feasible under the current market structure. Moreover, the regulatory framework must safeguard against firms exporting their monopoly power in other markets.

In passing the 1996 Act Congress took radical steps to restructure U.S. telecommunications markets. These steps may result in very significant benefits to consumers of telecommunications services, telecommunications carriers, and telecommunications equipment manufacturers. But the degree of success of the 1996 Act depends crucially on its implementation through decisions of the Federal Communication Commission and state public utility commissions and the outcome of the various court challenges that these decisions face.

The 1996 Act envisions a network of interconnected networks composed of complementary components that generally provide both competing and complementary services. The 1996 Act uses both structural and behavioral instruments to accomplish its goals. The Act attempts to reduce regulatory barriers to entry and competition. It outlaws artificial barriers to entry in local exchange markets in an attempt to accomplish the maximum possible competition. Moreover, it mandates interconnection of telecommunications networks, unbundling, nondiscrimination, and cost-based pricing of leased parts of the network, so that competitors can enter easily and compete component by component and service by service.

The 1996 Act imposes conditions to ensure that de facto monopoly power is not exported to vertically related markets. Thus, the Act requires that competition be established in local markets before the incumbent local exchange carriers are allowed in long distance.

The Act preserves subsidized local service to achieve "Universal Service" but imposes the requirement that subsidization be transparent and that subsidies be raised in a competitively neutral manner. Thus, the Act leads the way to the elimination of subsidization of Universal Service through the traditional method of high access charges.

The 1996 Act crystallized changes that had become necessary because of technological progress. Rapid technological change has always been the original cause of regulatory change. The radical transformation of the regulatory environment and market conditions that are presently taking place as a result of the 1996 Act are no exception.

\section{History}

Telecommunications has traditionally been a regulated sector of the U.S. economy. Regulation was imposed in the early part of this century and remains until today in various parts of the industry. ${ }^{3}$ The main idea behind regulation was that it was necessary because the market for telecommunications services was a natural monopoly, and therefore a second competitor would not survive. 
As early as 1900, it was clear that all telecommunications markets were not natural monopolies, as evidenced by the existence of more than one competing firm in many regional markets, prior to the absorption of most of them in the Bell System. Over time, it became clear that some markets were not natural monopolies any more, and that it was better to allow competition in those markets while keeping the rest regulated.

The market for telecommunication services and for telecommunications equipment went through various stages of competitiveness since the invention of the telephone by Alexander Graham Bell. After a period of expansion and consolidation, by the 1920 AT\&T had an overwhelming majority of telephony exchanges and submitted to State regulation. Federal regulation was instituted by the 1934 Telecommunication Act, which established the Federal Communications Commission.

Regulation of the U.S. telecommunications market was marked by two important antitrust lawsuits that the U.S. Department of Justice brought against AT\&T. In the first one, United States v. Western Electric, filed in 1949, the U.S. Department of Justice (DOJ) claimed that the Bell Operating Companies practiced illegal exclusion by buying only from Western Electric, a part of the Bell System. The government sought a divestiture of Western Electric, but the case was settled in 1956 with AT\&T agreeing not to enter the computer market, but retaining ownership of Western Electric.

The second major antitrust suit, United States v. AT\&T, was started in 1974 . The government alleged that AT\&T's relationship with Western Electric was illegal, and that AT\&T monopolized the long-distance market. The DOJ sought divestiture of both manufacturing and long distance from local service. The case was settled by the Modified of Final Judgement (MFJ). This decree broke away from AT\&T seven Regional Bell Operating Companies (RBOCs). Each RBOC was comprised of a collection of local telephone companies that were part of the original AT\&T. RBOCs remained regulated monopolies, each with an exclusive franchise in its region.

Microwave transmission was a major breakthrough in long-distance transmission that created the possibility of competition in long distance. The breakup of AT\&T crystallized the recognition that competition was possible in long distance, while the local market remained a natural monopoly. The biggest benefits to consumers during the past fifteen years have come from the long-distance market, which, during this period was transformed from a monopoly to an effectively competitive market. However, often consumers do not reap the full benefits of cost reductions and competition because of an antiquated regulatory framework that, ironically, was supposed to protect consumers from monopolistic abuses but instead protects the monopolistic market structure.

Competition in long distance has been a great success. The market share (in minutes of use) of AT\&T fell from almost 100 percent to 53 percent at the end of 1996 . Since the MFJ, the number of competitors in the long distance market has increased dramatically. There are five large facilities-based competitors: AT\&T, MCI, Sprint, LDDS-Worldcom, and Frontier. ${ }^{4}$ There is also a large number of "resellers" that buy wholesale service from the facilities-based longdistance carriers and sell to consumers. For example, currently, there are about 500 resellers competing in the California interexchange market, providing very strong evidence for the ease of entry into this market. At least twenty new firms entered the California market in each year since 1984. At present, there are at least five "out of region" RBOCs providing service in California through affiliates. In California, the typical consumer can choose from at least 150 long distance companies.

Prices of long-distance phone calls have decreased dramatically. The average revenue per minute of AT\&T's switched services has been reduced by 62 percent between 1984 and 1996 . AT\&T was declared "nondominant" in the long-distance market by the FCC in $1995 .{ }^{5}$ Most economists agree that presently the long-distance market is effectively competitive. 
RBOCs actively petitioned the U.S. Congress to be allowed to enter the long-distance market, from which they were excluded by the MFJ. The MFJ prevented RBOCs from participation in long distance because of the anticompetitive consequences that this would have for competition in long distance. The anticompetitive effects would arise because of the control by RBOCs of essential "bottleneck" inputs for long-distance services, such as terminating access to long-distance companies of phone calls to customers that live in the local companies' area.

A long-distance phone call is carried by the local telephone companies at the place it originates and the place it terminates, and only in its long-distance part by a long-distance company. Thus, "originating access" and "terminating access" are provided by local exchange carriers to long-distance companies and are essential bottleneck inputs for long-distance service. Origination and termination of calls are extremely lucrative services. ${ }^{6}$ Terminating access has an average cost (in most locations) of $\$ 0.002$ per minute. Its regulated prices vary. A typical price is $\$ 0.032$ per minute, charged by NYNEX. Such pricing implies a profit rate of 1500 percent. $^{7}$ Access charges reform is one of the key demands of the procompetitive forces in the current deregulation process.

The great success of competition in long distance allowed the U.S. Congress to appear "balanced" in the Telecommunications Act of 1996 by establishing competition in local telephony, while allowing RBOCs into long distance after they meet certain conditions. However, the transition of local markets to effective competition will not be as easy or as quick as in the long- distance markets. This is because of the nature of the product and the associated economics.

Many telecommunications companies are presently trying to be in as many markets as possible so that they can bundle the various products. Companies believe that consumers are willing to pay more for bundled services for which the consumer receives a single bill. Bundling also discourages consumers from migrating to competitors, who may not offer the complete collection of services, so consumer "churn" is expected to be reduced.

\section{Entry in Local Services}

Currently, the "last mile" of the telecommunications network closest to the consumer (the "local loop") remains a bottleneck controlled by a local exchange carrier ("LEC"). The Telecommunications Act of 1996 boldly attempts to introduce competition in this last bottleneck, and, before competition takes hold, the Act attempts to imitate competition in the local exchange.

To facilitate entry in the local exchange, the Act introduces two novel ways of entry besides entry through the installation of owned facilities. The first way allows entry in the retailing part of the telecommunications business by requiring incumbent local exchange carriers (ILECs) to sell at wholesale prices to entrants any retail service that they offer. Such entry is essentially limited to the retailing part of the market.

The second and most significant novel way of entry introduced by the Act is through leasing of unbundled network elements from incumbents. In particular, the Act requires that ILECs unbundle their networks; and that they offer for lease to entrants network components (unbundled network elements, "UNEs") "at cost plus reasonable profit." " Thus, the Act envisions the telecommunications network as a decentralized network of interconnected networks.

Many firms, including the large interexchange carriers AT\&T and MCI, attempted to enter the market through "arbitration" agreements with ILECs under the supervision of state regulatory commissions, according to the procedure outlined by the Act. The arbitration process proved to be extremely long and difficult, with continuous legal obstacles and appeals raised by the ILECs. To this date (February 1998), two years after the signing of the Act by President Clinton, 
arbitrations have been concluded in very few states, and entry in the local exchange has been minimal.

\section{Entry of RBOCs in Long -Distance Service}

RBOCs (Ameritech, Bell Atlantic, BellSouth, SBC and USWest) have 89 percent of the telephone access lines nationwide. Most of the remainder belongs to GTE and independent franchise holders. Competitive access providers (who did not hold a franchise monopoly) have less than 1 percent of residential access lines nationwide. In addition to providing access to longdistance companies, local exchange carriers also provide lucrative "custom local exchange services" (CLASS), such as call waiting, conference calling, and automatic number identification. Basic local service provided by LECs is considered not to be particularly profitable.

The Act allows for entry of RBOCs in long distance once a list of requirements has been met, and the petitioner has proved that its proposal is in the public interest. These requirements can be met only when the market for local telecommunications services becomes sufficiently competitive. If the local market is not competitive when an incumbent LEC monopolist enters into long distance, the LEC can leverage its monopoly power to disadvantage its long-distance rivals by increasing their costs in various ways, and by discriminating against them in its pricing.

In allowing entry of local exchange carriers into the long-distance market, the Act tries not to endanger competition that has developed in long distance by premature entry of RBOCs in the long distance market. However, on this issue, the Act's provisions guarding against premature entry may be insufficient. Hence, to guard against anticompetitive consequences of premature entry of RBOCs in long distance, there is a need of a deeper analysis of the consequences of such entry on competition and on consumers' social welfare.

\section{THE IMPACT OF WIRELESS (CELLULAR, SATELLITE AND PCS) AND CABLE TV}

During the past fifteen years there has been a tremendous (and generally unanticipated) expansion of the mobile phones market. The very significant growth has been limited by relatively high prices resulting from the prevention of entry of more than two competitors in each metropolitan areas; and the standard billing arrangement that imposes a fee on the cellular customer for receiving (as well as initiating) calls.

However, during the past three years, the FCC has auctioned parts of the electromagnetic spectrum that will enable the transmission of personal communication services (PCS) signals. ${ }^{10}$ The auctioned spectrum will be able to support up to five additional carriers in the major metropolitan markets. ${ }^{11}$ Although the PCS spectrum band is different than the traditional cellular bands, PCS is predicted to be a low-cost, high-quality, mobile alternative to traditional phone service. Other wireless services may chip away at the ILECs markets, especially in high capacity access services. ${ }^{12}$ The increase in the number of competitors has already created very significant decreases in prices of mobile phone services.

By its nature, PCS is positioned between fixed local service and traditional wireless (cellular) service. Presently there is a very significant price difference between the two services. Priced between the two, PCS will first draw consumers from cellular in large cities, and later on will be a serious threat to fixed local service. AT\&T has recently announced that it will use

some of the spectrum that it acquired in the PCS auctions to implement a fixed wireless service ("telepoint"), a close (and maybe superior) substitute to fixed wire service. ${ }^{13}$ 
Industry analysts have been predicting the impending entry of cable television in telephony for many years. In spite of numerous trials, such entry in traditional telecommunications services has not materialized. There are a number of reasons for this:

1. To provide telephone service, cable television providers needed to upgrade their networks from analog to digital.

2. They need to add switching.

3. Most of the cable industry has taken a high debt load and is unable to make the required investments in the short run.

If and when it is able to provide switching, cable television would have a significant advantage over regular telephone lines. Cable TV lines that reach the home have a significantly higher bandwidth capacity that regular twisted pair lines. This is not important for regular voice telephony, but it is crucially important for applications on the world wide web that require high bandwidth capacity. Companies such as @home and WebTV are utilizing this capacity to provide bundles of Internet and traditional TV services. Often these services do not allow for two-way communication but rather rely on a telephone line for transmissions from the home to the Internet Service Provider (ISP), who is expected to require only low bandwidth.

\section{THE COMING WORLD}

The market structure in the telecommunications sector two years ahead will depend crucially on the resolution of the LECs legal challenges to the 1996 Telecommunications Act. ${ }^{14}$ These challenges have derailed the implementation process of the Act and have increased significantly the uncertainty in the telecommunications sector. Long-distance companies have been unable to enter the local exchange markets by leasing unbundled network elements (UNEs), because the arbitration process that started in April 1996 has resulted in final prices in only a handful of states. Instead, AT\&T acquired TCG that owns some local exchange infrastructure, and MCI merged with Worldcom, which had just merged with Brooks Fiber that also owns some infrastructure in local exchange markets. Meanwhile Pacific Bell was acquired by SBC, and NYNEX by Bell Atlantic, in spite of antitrust objections, in an attempt of the RBOCs to maximize their foothold, looking forward to the time when they will be allowed to provide longdistance service. ${ }^{15}$

The intent of the 1996 Act was to promote competition and the public interest. It will be a significant failure of the U.S. political, legal, and regulatory systems if the interests of entrenched monopolists rather than the public interest as expressed by the U.S. Congress dictate the future of the U.S. telecommunications sector.

Whatever the outcomes of the legal battles, the existence of arbitrage and the intensification of competition necessitate cost-based pricing and will create tremendous pressure on traditional regulated prices that are not cost-based. Prices that are not based on cost will prove unsustainable.

Computers are likely to play a bigger role as telephone appliances and in running intermediate- size networks that will compete with LECs. Computer-based telephone interfaces will become the norm. Firms that have significant market power in computer interfaces, such as Microsoft, may play a significant role in telephony. Hardware manufacturers, especially firms like Cisco, Intel, and 3Com that make switches and local networks, will play a much more central role in telephony. Internet telephony is expected to grow fast.

Finally, I expect that, slowly but steadily, telecommunications will drift away from the technical standards of signalling system seven (SS7) established by AT\&T before its breakup. As different methods of transmission and switching take a foothold, and as new interfaces 
become available, wars over technical standards are very likely. This will further transform telecommunications from the traditional quiet landscape of regulated utilities to the mad dash world of software and computer manufacturing. This change will create significant business opportunities for entrants and impose significant challenges on traditional telecommunications carriers.

\section{FOOTNOTES}

1. Critical points in this development were the emergence of GOPHER in the late1980s and MOSAIC by 1990.

2 A large enough bandwidth increases the probability that fewer packets will be lost. And, if each packet is send a number of times, it is much more likely that each packet will arrive at the destination at least once, and the quality of the phone call will not deteriorate. Thus, the provider can adjust the quality level of an Internet call by guaranteeing a lot of bandwidth for the transmission, and by sending the packets more than once. This implies that the quality of an Internet call is variable and can be adjusted upward using the variables mentioned. Thus, high-quality voice telephony is immediately feasible in intranets since intranets can guarantee a sustained large enough bandwidth. There is no impediment to the quality level of a phone call that is picked from the PSTN at the local switch, carried over long distance on leased lines, and redelivered to the PSTN at the destination local switch, using the recently introduced Lucent switches. For Internet calls that originate or terminate in computers, the method of resending packets can be used on the Internet to increase the quality of the phone call, as long as there is sufficient bandwidth between the computer and the local telephone company switch. The fidelity of calls can also be enhanced by manipulation of the sound frequencies. This can be done, for example, through the elemedia series of products by Lucent.

3 The telecommunications sector is regulated both by the Federal Government through the Federal Communications Commission ("FCC") and by all States, typically through a Public Utilities Commission ("PUC") or Public Service Commission. Usually a PUC also regulates electricity companies.

${ }^{4}$ These will be limited to four if the merger of MCI and WORLDCOM is approved by regulators and antitrust authorities. Frontier is a new name for Rochester Telephone.

${ }^{5}$ See Federal Communications Commission (1995).

${ }^{6}$ These fees are the single largest cost item in the ledgers of AT\&T.

${ }^{7}$ Termination pricing varies. Pacific Bell, under pressure from the California Public Utilities Commission, now has an access charge of $\$ 0.016$ per minute, giving it a profit rate of $700 \%$.

8 The FCC and state regulatory commissions have interpreted these words to mean Total Element Long Run Incremental Cost (TELRIC), which is the forward looking, long-run, (minimized) economic cost of an unbundled element and includes the competitive return on capital.

${ }^{9}$ See Economides (1998).

10 In spite of this and other auctions of spectrum, the FCC does not have a coherent policy of efficient allocation of electromagnetic spectrum. For example, recently, the FCC gave for free huge chunks of electromagnetic spectrum to existing TV stations so that they may provide high definition television. Some of the recipients have publicly stated that they intend to use the spectrum to broadcast regular TV channels and information services, rather than HDTV. 


\footnotetext{
${ }^{11}$ We don't expect to see five entrants in all markets because laxity in the financial requirements of bidders resulted in default of some of the high bidders in the PCS, prompting a significant dispute regarding their financial and other obligations.
}

12 The so-called "wireless loop" proposes to bypass the ILECs cabling with much less outlay for equipment. Trials are underway to test certain portions of the radio spectrum that were originally set aside for other applications: MMDS for "wireless cable" and LMDS as "cellular television."

13 The second impediment to wider use of mobile phones seems also likely to disappear. On January 26, 1998, AT\&T announced that it will offer mobile service with billing of incoming calls to the originator of the call.

${ }^{14}$ In one of the major challenges, GTE and a number of RBOCs appealed (among others) the FCC (1996) rules on pricing guidelines to the $8^{\text {th }}$ Circuit. The plaintiffs won the appeal; the FCC appealed to the Supreme Court, which accepted the case. A final outcome is expected in October 1998.

15 Recently, SBC announced its intention to buy Southern New England Telephone ("SNET") one of the few companies, which, as an independent, was not bound by MFJ restrictions and has already entered into long distance.

\section{REFERENCES}

Crandall, Robert W., (1991), After the Breakup: U.S. Telecommunications in a More Competitive Era. Brookings Institution, Washington, DC, 1991.

Economides, Nicholas, (1996), "The Economics of Networks," International Journal of Industrial Organization, vol. 14, no. 2, pp. 675-699.

Economides, Nicholas, (1998), "Raising Rivals' Costs in Complementary Goods Markets: LECs Entering into Long Distance and Microsoft Bundling Internet Explorer," forthcoming in the 1997 Telecommunications Policy Research Conference Volume.

Economides, Nicholas, Giuseppe Lopomo and Glenn Woroch, (1996), "Regulatory Pricing Policies to Neutralize Network Dominance," Industrial and Corporate Change, vol. 5, no. 4, pp. 1013-1028.

Federal Communications Commission, (1995), "In the Matter of Motion of AT\&T Corp. to be Reclassified as a Non-Dominant Carrier," CC Docket No. 95-427, Order, Adopted October 12, 1995.

Federal Communications Commission, (1996), "First Report and Order," CC Docket N. 96-98, CC Docket No. 95-185, Adopted August 8, 1996.

Mitchell, Bridger, and Ingo Vogelsang, (1991), Telecommunications Pricing: Theory and Practice. Cambridge University Press.

Noll, Roger G., and Bruce Owen, (1989), "The Anti-competitive Uses of Regulation: United States v. AT\&T," in John E. Kwoka and Lawrence J. White, eds., The Antitrust Revolution. New York: Harper Collins, 1989, pp. 290-337. 